1352-2310(95)00436-X

\title{
LOW MOLECULAR WEIGHT DICARBOXYLIC ACIDS AND RELATED POLAR COMPOUNDS IN THE REMOTE MARINE RAIN SAMPLES COLLECTED FROM WESTERN PACIFIC
}

\author{
RICHARD SEMPÉRÉ* and KIMITAKA KAWAMURA \\ Department of Chemistry, Faculty of Science, Tokyo Metropolitan University, 1-1 Minami-Ohsawa, \\ Hachioji, Tokyo 192-03, Japan
}

(First received 25 January 1995 and in final form 29 September 1995)

\begin{abstract}
During the western Pacific Ocean cruise of R/V Hakuho-Maru $\left(20^{\circ} \mathrm{N}-40^{\circ} \mathrm{S}\right)$, fourteen rainwater samples were collected. They were studied by a capillary gas chromatography (GC) and GC-mass spectrometry (GC/MS) for the molecular distributions of $\mathrm{C}_{2}-\mathrm{C}_{10} \alpha, \omega$-dicarboxylic acids and related polar compounds, i.e. ketoacids $\left(\mathrm{C}_{2}-\mathrm{C}_{9}\right)$ and $\alpha$-dicarbonyls $\left(\mathrm{C}_{2}-\mathrm{C}_{3}\right)$. Samples were also analysed for dissolved (DOC) and total organic carbon (TOC). Total diacid concentration range was 36-959 $\mu \mathrm{g} \ell^{-1}$ and accounted for $3 \%$ (av.) of TOC $\left(1.2-2.5 \mathrm{mgC} \ell^{-1}\right.$ ), which is much higher than the previous numbers found in Tokyo rain samples (av. 1\%). This indicates that low molecular weight dicarboxylic acids are an important class of organic compounds in the marine rains. All the samples showed that the smallest diacid (oxalic acid) which comprised $50 \%$ of the total diacids was the most abundant followed by malonic $\left(\mathrm{C}_{3}\right)$ or succinic acid $\left(\mathrm{C}_{4}\right)$. The shorter chain diacids $\left(\mathrm{C}_{2}-\mathrm{C}_{4}\right)$ accounted for $63-90 \%$ (av. $80 \%$ ) of total diacids and their relative abundances increase from the Northern to the Southern Hemisphere. These results suggest that shorter chain diacids are in part produced in the marine atmosphere by photochemical oxidation of organic matter through the intermediates such as ketoacids and dicarbonyls. The major portion of diacids and their precursors is probably derived from the Asian and Australian continents by a long-range transport. Texte
\end{abstract}

Key word index: $\alpha, \omega$-dicarboxylic acids, ketoacids, $\alpha$-dicarbonyls, TOC, rainwaters, western Pacific.

\section{INTRODUCTION}

Low molecular weight (LMW) $\alpha, \omega$-dicarboxylic acids present in the atmosphere mainly originate from non-biological processes including incomplete combustion (Kawamura and Kaplan, 1987), ozonolysis and photooxidation of cyclic olefines and other organic compounds in the gaseous (Shuetzle et al., 1975; Grosjean et al., 1978; Grosjean and Friedlander, 1980; Norton et al., 1983; Handow et al., 1985; Hatakayama et al., 1985) and particulate phase (Kawamura and Gagosian, 1987; Stephanou, 1992; Stephanou and Stratigakis, 1993; Kawamura and Ikushima, 1993). In this manner, they have been reported as major organic compounds in urban (Cronn et al., 1977; Kawamura and Kaplan, 1987; Sempéré and Kawamura, 1994), remote marine (Stephanou, 1992; $\mathrm{Li}$ and Winchester, 1993; Kawamura and Usukura, 1993) or polar aerosol samples (Kawamura et al., 1992; 1996).

* Present address: Laboratoire de Microbiologie Marine, CNRS UPR 223, Case 907, Campus de Luminy, 13288 Marseille Cedex 9, France.
These water soluble compounds have been found at significant concentrations in wet precipitations from various locations (Lunde et al., 1977; Norton et al., 1983; Likens et al., 1983; Kawamura and Kaplan, 1983; Kawamura et al., 1985). However, to our knowledge, only few rainwater analyses were conducted by the use of $\mathrm{BF}_{3} / n$-butanol derivatization technique followed by gas chromatography (GC) determination which provides the molecular distributions of a homologous series of diacids $\left(\mathrm{C}_{2}-\mathrm{C}_{10}\right)$ (Sempéré and Kawamura, 1994). At this time and among other techniques this method allows better recoveries especially for shorter chain diacids and permits the detection of $\omega$-oxocarboxylic acids $\left(\mathrm{C}_{2}-\mathrm{C}_{10}\right)$, pyruvic acid and $\alpha$-dicarbonyls $\left(\mathrm{C}_{2}-\mathrm{C}_{3}\right)$ as well (Kawamura and Usukura, 1993; Kawamura, 1993). These results indicated that among these water soluble compounds, shorter chain diacids, particularly oxalic acid, are the most abundant in the urban (Kawamura and Kaplan, 1987; Kawamura and Ikushima, 1993; Sempéré and Kawamura, 1994; Khawaja, 1995) and marine aerosols (Kawamura and Usukura, 1993).

Determination of specific compounds in wet precipitations such as dicarboxylic acids can contribute 


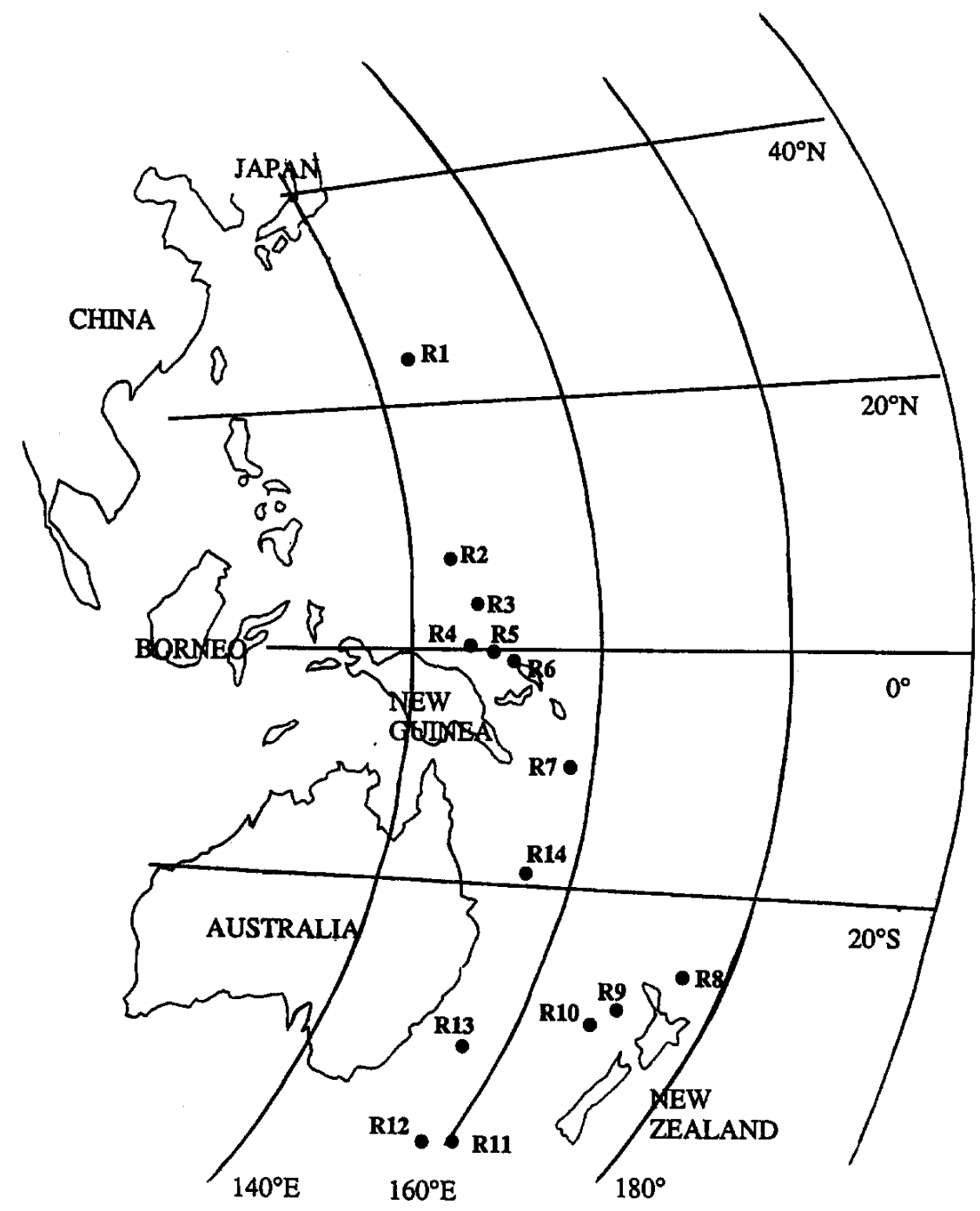

Fig. 1. Cruise track of R/V. Hakuho Maru: KH-92 started 16 September 1992 at Tokyo, Japan, and ended 26 October 1992 at Cairns, Australia. The circles indicate the sampling area for rainwater collection during the cruise.

to a better understanding of the transport of organic matter in the marine troposphere as well as to the heterogeneous oxidative processes such as oxidation/ reduction of iron in the atmosphere (Zuo and Hoigné, 1992, 1994; Hoigné et al., 1994). Moreover, LMW diacid emission and production represent a potential source of cloud condensation nuclei (Sempéré and Kawamura, 1994). However, only a few studies have been conducted on LMW diacids in remote marine atmosphere and there are no available data on the composition of $\mathrm{C}_{2}-\mathrm{C}_{10} \alpha, \omega$-dicarboxylic acids and related polar compounds in rains for such environments. In this paper we report the detailed distribution of the LMW dicarboxylic acids, ketoacids and dicarbonyls in the marine rainwater samples collected from western Pacific Ocean. We discuss the sources of these compounds and formation mechanisms.

\section{EXPERIMENTAL}

\section{Collection of rain samples}

Fourteen rainwater samples (R1-R14) were collected at the upper deck of $\mathrm{R} / \mathrm{V}$ Hakuho Maru (c. $14 \mathrm{~m}$ above the sea surface) during the KH92-4 cruise: August-October 1992. The cruise track is shown in Fig. 1. Rainwater samples were collected in a pre-cleaned brown glass bottle using a stainless steel rain collector with a cross-section of $2800 \mathrm{~cm}^{2}$ and protected from biodegradation with $\mathrm{HgCl}_{2}$ during sample collection. Sample storage was done at $4^{\circ} \mathrm{C}$ in darkness. The collected rainwater volumes and duration of rain ranged from 0.08 to $3.8 \ell$ and from 1 to $25.8 \mathrm{~h}$, respectively. Table 1 presents sample informations.

Determination of dicarboxylic acids and related compounds by $G C$ and $G C / M S$

Rain samples $(100-150 \mathrm{ml})$ were concentrated by a rotary evaporator under a vacuum and dried in a nitrogen stream. The dried samples were then reacted with $14 \%$ borontrifluoride $\left(\mathrm{BF}_{3}\right)$ in $n$-butanol $(0.3 \mathrm{ml})$ to derive carboxyl and 


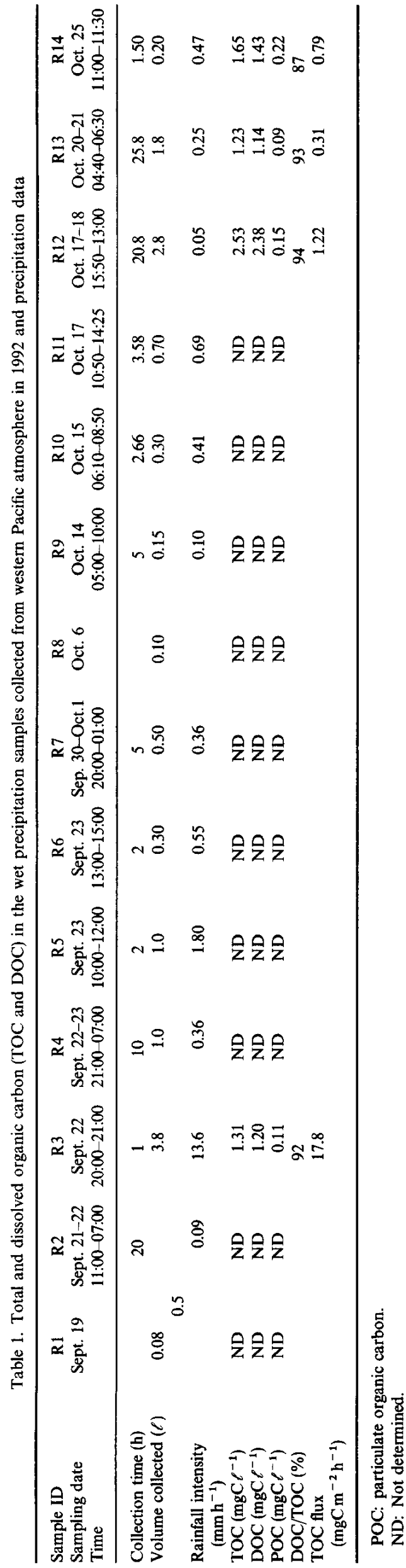

aldehyde groups to the butyl esters and dibutoxyacetals, respectively. The derivatives were extracted with $n$-hexane $(5 \mathrm{ml})$ in the presence of an organic free pure water $(3 \mathrm{ml})$ and acetonitrile $(0.3 \mathrm{ml})$ and the extracts were washed with the pure water $(3 \mathrm{ml} \times 2)$. The derivatives were concentrated to $50 \mu \mathrm{l}$ and determined with a Hewlett-Packard (HP 5890) gas chromatograph (GC) equipped with a split/splitless injector, a HP-5 fused silica capillary column $(0.32 \mathrm{~mm}$ i.d. $\times 25 \mathrm{~m} \times 0.52 \mu \mathrm{m}$ ), and an FID detector. Identification of the derivatives was performed by a comparison of GC retention times with those of authentic standards. Identification of diacids and ketoacids was confirmed by a GC/MS (Finnigan-MAT ITS-40).

Recoveries of oxalic acid were $70 \%$ whereas those of malonic, succinic and adipic acids were 77,86 and $90 \%$, respectively. Procedural blanks run with organic free pure water showed only small peaks of oxalic, pyruvic and phthalic acid derivatives in the GC chromatograms; they presented less than $4 \%$ of the actual samples. Analytical errors in the determination of diacids were within $5 \%$ for dicarboxylic acids, $15 \%$ for ketoacids, $7 \%$ for glyoxal and $26 \%$ for methylglyoxal based on duplicates analysis of the rain sample $R 1$. The concentrations of the acids presented here are corrected for the procedural blanks. The organic free water was prepared by boiling Milli $Q$ water with $\mathrm{KMnO}_{4}$ to oxidise organic impurities followed by subsequent distillation.

\section{Measurement of DOC and TOC in rain samples}

Wet precipitation samples were gently filtered with an allglass filter holder through a pre-heated $\left(500^{\circ} \mathrm{C}\right)$ Pallflex quartz fibre filter. An aliquot of unfiltered and filtered samples were taken in the pre-heated $\left(450^{\circ} \mathrm{C}\right)$ glass screw vials $(10 \mathrm{ml})$ with a Teflon lined cap. After acidification $(\mathrm{pH}<2)$ with $1.2 \mathrm{M} \mathrm{HCl}$ solution $(50 \mu \mathrm{l})$, the samples were bubbled with pure nitrogen gas for $5 \mathrm{~min}$ to purge inorganic carbon. The water sample $(20-50 \mu 1)$ was injected to a Shimadzu TOC-500 carbon analyser with a combustion column packed with a quartz wool impregnated with platinum. Injections were repeated five times for each sample. The data sets having the highest and lowest values were discarded, whereas the remaining three values were averaged and used for TOC and DOC calculation. The analytical precision of the procedure was within $2 \%$. Particulate organic carbon (POC) was calculated by the difference between TOC and DOC values. The carbon blank of the water used for the standard solutions was estimated to be $120 \mu \mathrm{g}$ by injections of different amount of pure water $(10-50 \mu 1)$ and subtracted for the standards. Unfortunately, we lost some samples for TOC measurements and are able to present only four remote marine (R3, R12 and $R 13$ and $R 14$ ) rainwater samples (Table 1).

\section{RESULTS AND DISCUSSION}

\section{TOC, DOC and POC in rain samples}

Table 1 gives results of total and dissolved organic carbon contents in the rain samples as well as precipitation data. TOC concentrations were found to be $1.2-2.5 \mathrm{mgC} \ell^{-1}(n=4$; av. $1.6 \pm 0.6)$. By contrast, previous results from Tokyo rains (Sempéré and Kawamura, 1994) showed higher TOC values ranging from 1.2 to $15.4 \mathrm{mgC}^{-1}$. Rain organic matter collected from remote sites probably originated from the continent-derived dusts and gases through long-range atmospheric transport (Simoneit, 1977; Duce and Duursma, 1977; Atlas and Giam, 1981; Gagosian et al., 1981, 1987; Kawamura and Gagosian, 1987) but 


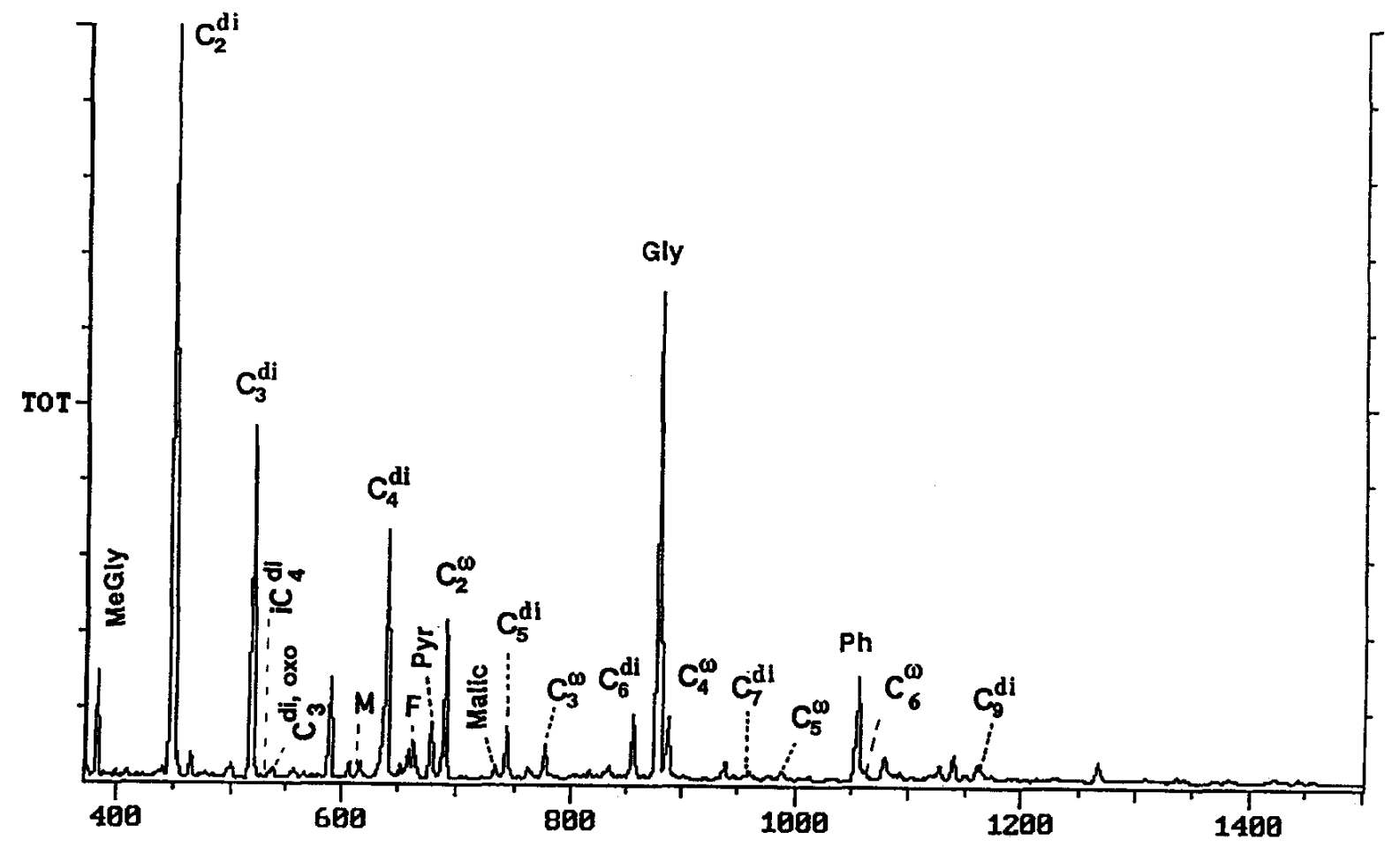

Scan Number

Fig. 2. A reconstructed total ion chromatogram (RIC) of the derivatives of dicarboxylic acids, ketocarboxylic acids and dicarbonyls isolated from the marine rain sample collected from the South Pacific (R13), October 1992. For abbreviation see Table 2. $C_{n}$ means dicarboxylic acid with $n$ carbon numbers. $i_{n}$ indicates branched chain (iso) diacid. $\mathrm{M}$ and $\mathrm{F}$ are abbreviations of unsaturated diacids: maleic and fumaric acids, respectively. $C_{n} \omega$ indicates $\omega$-oxocarboxylic acid with $n$ carbon numbers. Me-Gly, Pyr, Malic, Gly, Ph mean methylglyoxal, pyruvic, malic, glyoxylic and phthalic acids, respectively.

also from the ocean itself by direct sea-air gas exchange (Liss, 1973; Ratte et al., 1993) as well as by sea-salt spray and bubble bursting mechanisms (Woodcock, 1953; Barger and Garret, 1970; Marty et al., 1979).

Organic carbon in the precipitation was found mostly in the dissolved form (av. DOC \% in TOC $=92 \pm 3$, see Table 1) being similar to the number (70-99\%) reported for continental rains (urban and rural) (Liljestrand and Morgan, 1980; Likens et al., 1983; Kawamura and Kaplan, 1991; Sempéré and Kawamura, 1994). However, the 'dissolved' phase was here operationally defined as those passing through the quartz fibre filter (effective retention $=0.5$ $\mu \mathrm{m})$ thus, besides gaseous and truly dissolved organic compounds, rain DOC may comprise a continuum of small particles in colloidal size range as well. As seen in Table 1, TOC values are generally higher when rainfall intensity is low, indicating that weaker rains scavenge organic materials more efficiently per unit of precipitation volume. Based on our limited numbers of TOC measurements, organic carbon flux was calculated to range from $0.31 \mathrm{mgCm}^{-2} \mathrm{~h}^{-1}$ (duration of $25.8 \mathrm{~h}$ ) to $17.8 \mathrm{mgC} \mathrm{m}^{-2} \mathrm{~h}^{-1}$ (duration of $1 \mathrm{~h}$ ). For Enewetak Atoll rain samples (western North Pacific) which showed similar DOC values,
Zafiriou et al. (1985) estimated the wet plus dry deposition flux of $0.63 \mathrm{gC} \mathrm{m}^{-2} \mathrm{yr}^{-1}$, being in the same order of magnitude as the flux of organic carbon to the deep sea in the north central Pacific Ocean (Smith, 1987). These results suggest that rainwaters may provide locally and temporally significant amount of organic carbon to the surface seawater in the Pacific Ocean.

Identification and origin of dicarboxylic acids, ketoacids and dicarbonyls in rain samples

Figure 2 shows a reconstructed total ion chromatogram of derivatives of dicarboxylic acids, ketoacids and dicarbonyls isolated from the rain sample R13. A homologous series of straight-chain saturated $\left(\mathrm{C}_{2}-\mathrm{C}_{10}\right)$ dicarboxylic acids were identified in all the samples together with branched-chain (iso) saturated (methylmalonic: $\mathrm{C}_{4}$, methylsuccinic: $\mathrm{C}_{5}$ ), aliphatic unsaturated (maleic: cis $\mathrm{C}_{4}$; fumaric: trans $\mathrm{C}_{4}$ ), aromatic (phthalic: $\mathrm{C}_{8}$ ), oxo (oxomalonic: $\mathrm{C}_{3}$; 4-oxopimelic: $\mathrm{C}_{7}$ ) and hydroxy (malic: $\mathrm{C}_{4}$ ) diacids. The distribution of normal saturated diacids is generally characterised by a predominance of oxalic acid followed by either malonic $\left(C_{3}\right)$ or succinic $\left(C_{4}\right)$ acid. The diacids with more carbon numbers are less abundant (Fig. 2). Interestingly, similar chain-length distribution has 
been reported in urban rain and snow/sleet samples (Sempéré and Kawamura, 1994). Dicarboxylic acids have been considered to be mainly produced by secondary photochemical reactions occurring on anthropogenic and natural organic compounds (Grosjean et al., 1978; Grosjean and Friedlander, 1980; Yokouchi and Ambe, 1986; Kawamura and Gagosian, 1990) as well as direct emission from incomplete oxidation of fossil fuels during combustion processes (Kawamura and Kaplan, 1987). In the marine atmosphere, $C_{6}-C_{11}$ diacids with a predominance of $\mathrm{C}_{9}$ are produced by the photooxidation of biogenic unsaturated fatty acids (Kawamura and Gagosian, 1987).

In addition to diacids, low molecular weight ketoacids and dicarbonyls were also detected in the rain samples. The ketoacids detected include pyruvic acid $\left(\mathrm{C}_{3}\right)$ and a hornologous series of $\omega$-oxocarboxylic acids $\left(\mathrm{C}_{2}-\mathrm{C}_{9}\right)$. The group of dicarbonyls includes glyoxal $\left(C_{2}\right)$ and methylglyoxal $\left(C_{3}\right)$. Dicarbonyls may be intermediates in the photochemical oxidation reactions of aromatic hydrocarbons to oxalic acid (Norton et al., 1983). Diacids are c. 9 times more abundant than ketoacids which are considered as some of their precursors. On the other hand, a previous study reported a lower diacid/ketoacid ratio for snow/sleet (3) and rain (5) samples collected in Tokyo area (Sempéré and Kawamura, 1994). Some ketoacids (e.g. $\omega$-oxoacids) are probably intermediate products in the photochemical oxidations of organic compounds such as unsaturated fatty acids which also produce dicarboxylic acids (Kawamura and Gagosian, 1987). Therefore, it is likely that stronger photochemical oxidative processes are responsible for higher diacid/ketoacid ratios found in the marine rainwaters than in the continental rains.

Concentration levels of diacids, ketoacids and dicarbonyls in the western Pacific rainwaters

Table 2 gives concentrations of individual diacid as well as ketoacid and dicarbonyl in wet precipitation samples. Concentration range of total dicarboxylic acids $\left(\mathrm{C}_{2}-\mathrm{C}_{10}\right)$ was $35.9-959 \mu \mathrm{g} \ell^{-1}$ (av. $237 \mu \mathrm{g} \ell^{-1}$ ) which is similar to those reported for the urban rains $\left(12.2-538 \mu \mathrm{g} \ell^{-1}\right.$, av. $186 \mu \mathrm{g} \ell^{-1}$; Sempéré and Kawamura, 1994). Significantly high concentrations (93.2-626 $\mu \mathrm{g} \ell^{-1}$ ) were obtained for rain samples collected in the western South Pacific (R6-R13; Fig. 3) and close to the equator ( $\mathrm{R} 5 ; 148 \mu \mathrm{g} \ell^{-1}$ ). The highest concentration $\left(959 \mu \mathrm{g} \ell^{-1}\right)$ was obtained for the sample (R1) collected in the North Pacific. This area is known to receive high input of windblown dust from the deserts in Chira (Duce et al., 1990). However, the diacids accounted for $1-5 \%$ (av. $3 \%$ ) of DOC in the remote marine rainwaters being c. 3 times higher than those $(0.3-2 \%$; av. $1 \%)$ reported in the urban rains (Sempéré and Kawamura, 1994). These results are consistent with our aerosol studies (Sempéré and Kawamura, in press) and suggest that dicarboxylic acids detected in the western Pacific atmosphere are significantly produced in the marine atmosphere probably by the photochemical oxidation of various organic compounds including hydrocarbons, aldehydes and carboxylic acids. Based on precipitation data, a flux of the diacids was calculated to range from 4.51 to $487 \mu \mathrm{g} \mathrm{m}^{-2} \mathrm{~h}^{-1}$, (av. $122 \mu \mathrm{g} \mathrm{m}^{-2} \mathrm{~h}^{-1}$ ).

Ketoacid concentration range is $3.51-106 \mu \mathrm{g} \ell^{-1}$ (av. $29.4 \mu \mathrm{g} \ell^{-1}$ ) being in the same order of magnitude as those reported in continental rain samples from Tokyo (3.73-93.5 $\mu \mathrm{g} \ell^{-1}$; av. 40.4 $\mu \mathrm{g} \ell^{-1}$ ). The highest value was observed in the South Pacific sample (R10: $106 \mu \mathrm{g} \ell^{-1}$ ). This feature was mainly due to the high content of pyruvic acid $\left(87.2 \mu \mathrm{g} \ell^{-1}\right)$ whereas $\omega$-oxoacids showed a concentration maximum in the R11 sample (32.1 $\left.\mu \mathrm{g} \ell^{-1}\right)$. Total ketoacids accounted for $0.2-0.6 \%$ (av. $0.4 \%$ ) of DOC which is higher than the value found for Tokyo rainwater samples $(0.06$ $0.6 \%$ : av. $0.3 \%$; Sempéré and Kawamura, 1994), being consistent with the case of diacid considerations. Flux of ketoacids was calculated to range from 0.59 to $82.2 \mu \mathrm{g} \mathrm{m}^{-2} \mathrm{~h}^{-1}$ (av. $21.3 \mu \mathrm{g} \mathrm{m}^{-2} \mathrm{~h}^{-1}$ ).

Concentrations of dicarbonyls were lower than diacids as well (Table 2; Fig. 3): their concentration range is $0.69-37.8 \mu \mathrm{g} \ell^{-1}$ (av. $11.8 \mu \mathrm{g} \ell^{-1}$ ) being in the same order of magnitude with that reported for the Tokyo rain samples $\left(0.57-88.8 \mu \mathrm{g} \ell^{-1} ; \quad\right.$ av. $28.1 \mu \mathrm{g} \ell^{-1}$ ). They accounted for $0.1-0.7 \%$ (av. $0.4 \%$ ) of DOC which is twice the value reported for the Tokyo rains (Sempéré and Kawamura, 1994). Higher dicarbonyl concentrations were observed in the samples collected in the higher latitudes of the Southern Hemisphere (e.g. R11-R13 : 16.3-37.8 $\mu \mathrm{g} \ell^{-1}$ ). Glyoxal was more abundant than methylglyoxal in the South Pacific and vice versa in the North Pacific. Based on the concentration and precipitation data, a flux of the dicarbonyls was calculated to range from 0.20 to $42.2 \mu \mathrm{g} \mathrm{m}^{-2} \mathrm{~h}^{-1}$ (av. 10.6 $\mu \mathrm{g} \mathrm{m}^{-2} \mathrm{~h}^{-1}$ ).

Molecular distribution of dicarboxylic acids, ketoacids and dicarbonyls in the western Pacific atmosphere

The molecular distributions of dicarboxylic acids in the western Pacific rainwaters were characterised by a predominance of shorter chain diacids. Oxalic acid $\left(\mathrm{C}_{2}\right)$ was the most abundant species comprising $39-64 \%$ (av. $50 \%$ ) of the total diacids detected (Table 3, Fig. 4a). Preferential photochemical production of oxalic acid has been observed in the urban atmosphere where its concentration is well correlated with oxidant concentrations (Kawamura and Ikushima, 1993). Oxalic acid produced by the oxidation of many precursors containing carbon number $>C_{2}$ is an end product of the photochemical oxidation reactions and can be accumulated in the atmosphere (Kawamura and Ikushima, 1993). The predominance of oxalic acid has been observed in the urban rain and snow samples and ice/snow samples from Greenland. However, the relative abundance of oxalic acid in the total diacids (av. $50 \%$ ) in the remote marine rainwaters is much higher than those in urban rain $(37 \%)$, snow/sleet $(28 \%)$ samples (Sempéré and Kawamura, 1994) and Greenland ice/snow samples (28\%) (Kawamura 


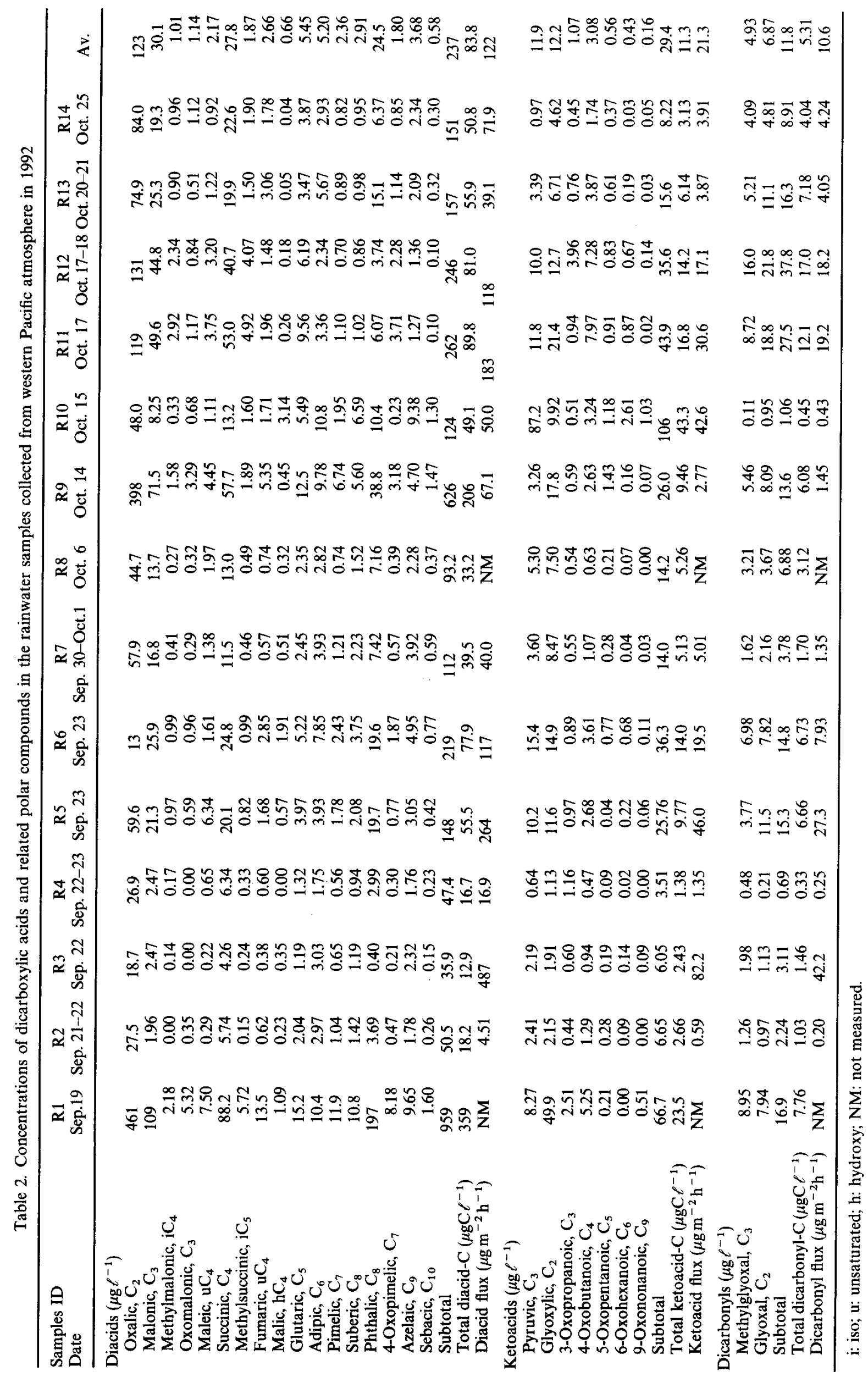




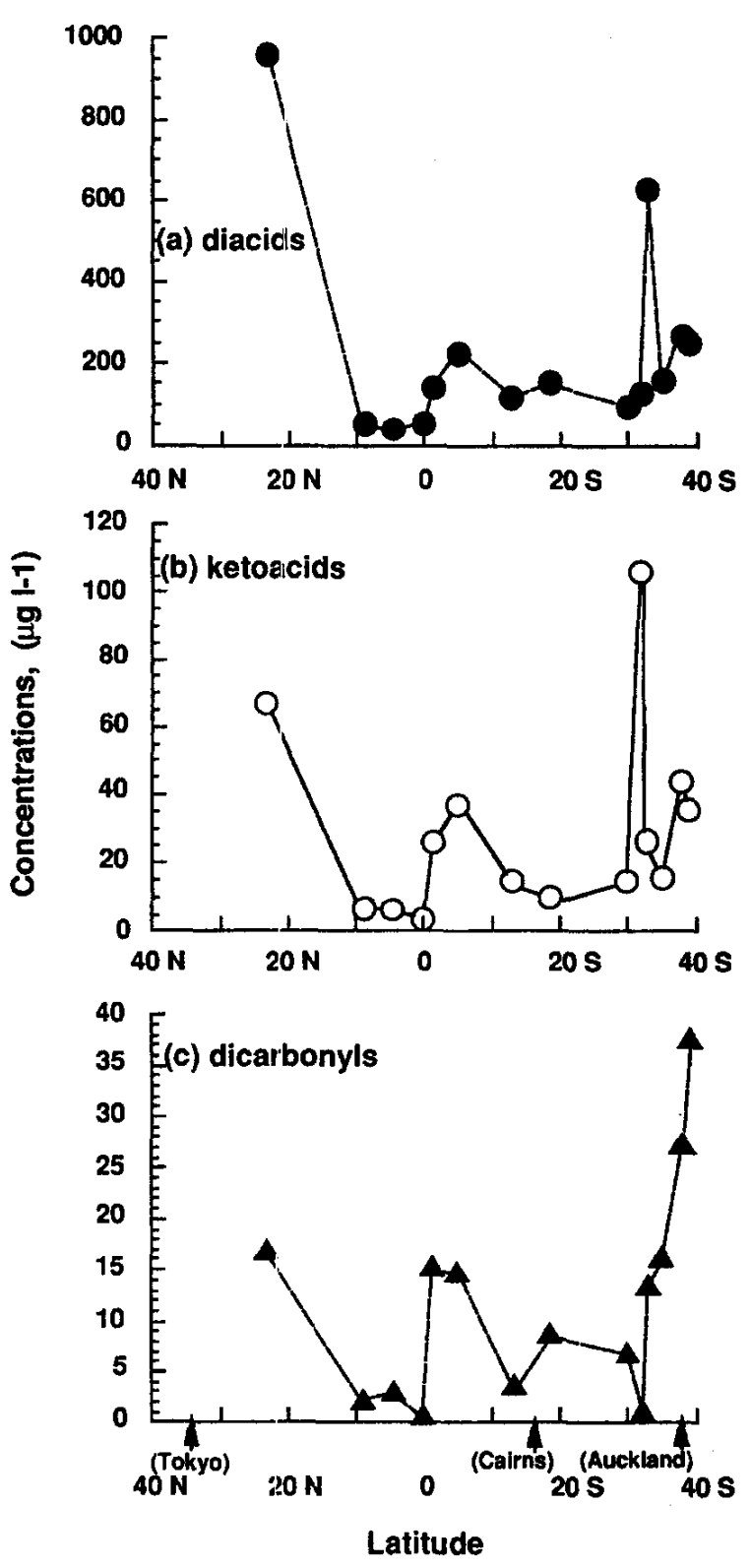

Fig. 3. Latitudinal distribution of the dicarboxylic acid (a), ketoacid (b) and dicarbonyl (c) concentrations in the western Pacific rainwater samples, September-October 1992.

and Yasui, 1991). These results suggest that photochemical reactions to produce oxalic acid is more significant in the marine atmosphere than continental air.

Interestingly, oxalic acid has been found in eastern Pacific Ocean waters by the use of HPLC (Steinberg and Bada, 1984). Unfortunately, these authors did not collect surface waters but reported oxalic acid concentrations of $c .10 \mu \mathrm{g} \ell^{-1}$ at $75 \mathrm{~m}$ depth. They considered that oxalic acid is a product and substrate of marine bacteria. However, concentrations of oxalic acid in the western Pacific rainwaters were found to be 2-40 times higher than those reported in seawater, suggesting that sea-to-air transport of oxalic acid is not an important process.
Table 3. Relative abundance $(\%)$ of dicarboxylic acids and related polar compounds in the rainwater samples $(n=14)$ collected from western Pacific atmosphere in 1992

\begin{tabular}{|c|c|c|}
\hline Classes of compounds & Range & Average \\
\hline \multicolumn{3}{|l|}{ Diacids (\%) } \\
\hline Oxalic, $\mathrm{C}_{2}$ & $39-64$ & $50 \pm 6$ \\
\hline Malonic, $\mathbf{C}_{3}$ & $3.9-19$ & $12 \pm 5$ \\
\hline Methylmalonic, $\mathrm{iC}_{4}$ & $0.0-1.1$ & $0.5 \pm 0.3$ \\
\hline Oxomalonic, $\mathrm{C}_{3}$ & $0.0-0.7$ & $0.4 \pm 0.2$ \\
\hline Maleic, $\mathrm{uC}_{4}$ & $0.6-4.3$ & $1.2 \pm 10$ \\
\hline Succinic, $\mathrm{C}_{4}$ & $9.2-20$ & $13 \pm 3$ \\
\hline Methylsuccinic, $\mathrm{iC}_{5}$ & $0.3-1.9$ & $0.8 \pm 0.5$ \\
\hline Fumaric, $\mathrm{uC}_{4}$ & $0.5-2.0$ & $1.1 \pm 0.4$ \\
\hline Malic, $\mathrm{hC}_{4}$ & $0.0-2.5$ & $0.5 \pm 0.6$ \\
\hline Glutaric, $\mathrm{C}_{5}$ & $1.6-4.0$ & $2.8 \pm 1$ \\
\hline Adipic, $\mathrm{C}_{6}$ & $1.0-8.7$ & $3.6 \pm 2$ \\
\hline Pimelic, $\mathrm{C}_{7}$ & $0.3-2.0$ & $1.1 \pm 1$ \\
\hline Suberic, $C_{8}$ & $0.4-3.3$ & $1.7 \pm 1$ \\
\hline Phthalic, $\mathrm{C}_{8}$ & $1.1-21$ & $7.4 \pm 5$ \\
\hline 4-Oxopimelic, $\mathrm{C}_{7}$ & $0.2-1.4$ & $0.7 \pm 0.3$ \\
\hline Azelaic, $\mathrm{C}_{9}$ & $0.5-7.6$ & $2.7 \pm 2$ \\
\hline Sebacic, $C_{10}$ & $0.04-1.1$ & $0.4 \pm 0.2$ \\
\hline Total & 100 & \\
\hline \multicolumn{3}{|l|}{ Ketoacids (\%) } \\
\hline Pyruvic, $\mathrm{C}_{3}$ & $12-83$ & $31 \pm 18$ \\
\hline Glyoxylic, $\mathrm{C}_{2}$ & $9.4-75$ & $45 \pm 16$ \\
\hline 3-Oxopropanoic, $\mathrm{C}_{3}$ & $0.5-33$ & $6.7 \pm 8$ \\
\hline 4-Oxobutanoic, $\mathrm{C}_{4}$ & $3.1-25$ & $13 \pm 7$ \\
\hline 5-Oxopentanoic, $\mathrm{C}_{5}$ & $0.2-4.5$ & $2.5 \pm 2$ \\
\hline 6-Oxohexanoic, $\mathrm{C}_{6}$ & $0.0-2.5$ & $1.2 \pm 1$ \\
\hline 9-Oxononanoic, $\mathrm{C}_{9}$ & $0.0-1.5$ & $0.4 \pm 0.4$ \\
\hline Total & 100 & \\
\hline \multicolumn{3}{|l|}{ Dicarbonyls $(\%)$} \\
\hline Methylglyoxal, $\mathrm{C}_{3}$ & $10-69$ & $43 \pm 15$ \\
\hline Glyoxal, $\mathrm{C}_{2}$ & $31-90$ & $57 \pm 15$ \\
\hline Total & 100 & \\
\hline
\end{tabular}

$\mathrm{i}$ : iso. u:unsaturated. h: hydroxy.

The second most abundant species was either succinic $\left(\mathrm{C}_{4}\right)$, malonic $\left(\mathrm{C}_{3}\right)$ or phthalic acid $\left(\mathrm{C}_{8}\right)$ followed by glutaric $\left(\mathrm{C}_{5}\right)$, adipic $\left(\mathrm{C}_{6}\right)$ and azelaic $\left(\mathrm{C}_{9}\right)$ acids (Fig. 4). The $\mathrm{C}_{4}$ diacid comprised $9-20 \%$ (av. 13\%) whereas malonic acid comprised $4-19 \%$ (av. 12\%) of the total diacids (Table 3). Shorter chain diacids $\left(\mathrm{C}_{2}-\mathrm{C}_{4}\right)$ accounted for $c .80 \%$ of the total diacids and their relative abundances increase from the Northern to the Southern Hemisphere (Fig. 5). These results suggest that during long-range transport, photochemical oxidation of organic matter produced preferentially short chain diacids $\left(\mathrm{C}_{2}-\mathrm{C}_{4}\right)$. Actually, in the marine atmosphere, volatile fatty acids with carbon numbers $>\mathrm{C}_{4}$ as well as mid-chain 4-oxo ketocarboxylic acids which are both present in the marine atmosphere (Kawamura and Gagosian, 1988; 1990) may serve as precursor compounds of succinic acid. Conversely, hydroxylation of succinic acid produces malic acid which is further decomposed to malonic acid (Kawamura and Ikushima, 1993). Some of these species may further be oxidised to result in oxalic acid in the remote marine atmosphere.

Phthalic $\left(\mathrm{C}_{8}\right)$, glutaric $\left(\mathrm{C}_{5}\right)$ and azelaic acids $\left(\mathrm{C}_{9}\right)$ accounted for $1-21 \%$ (av. $7 \%$ ), $2-4 \%$ (av. $3 \%$ ) and 

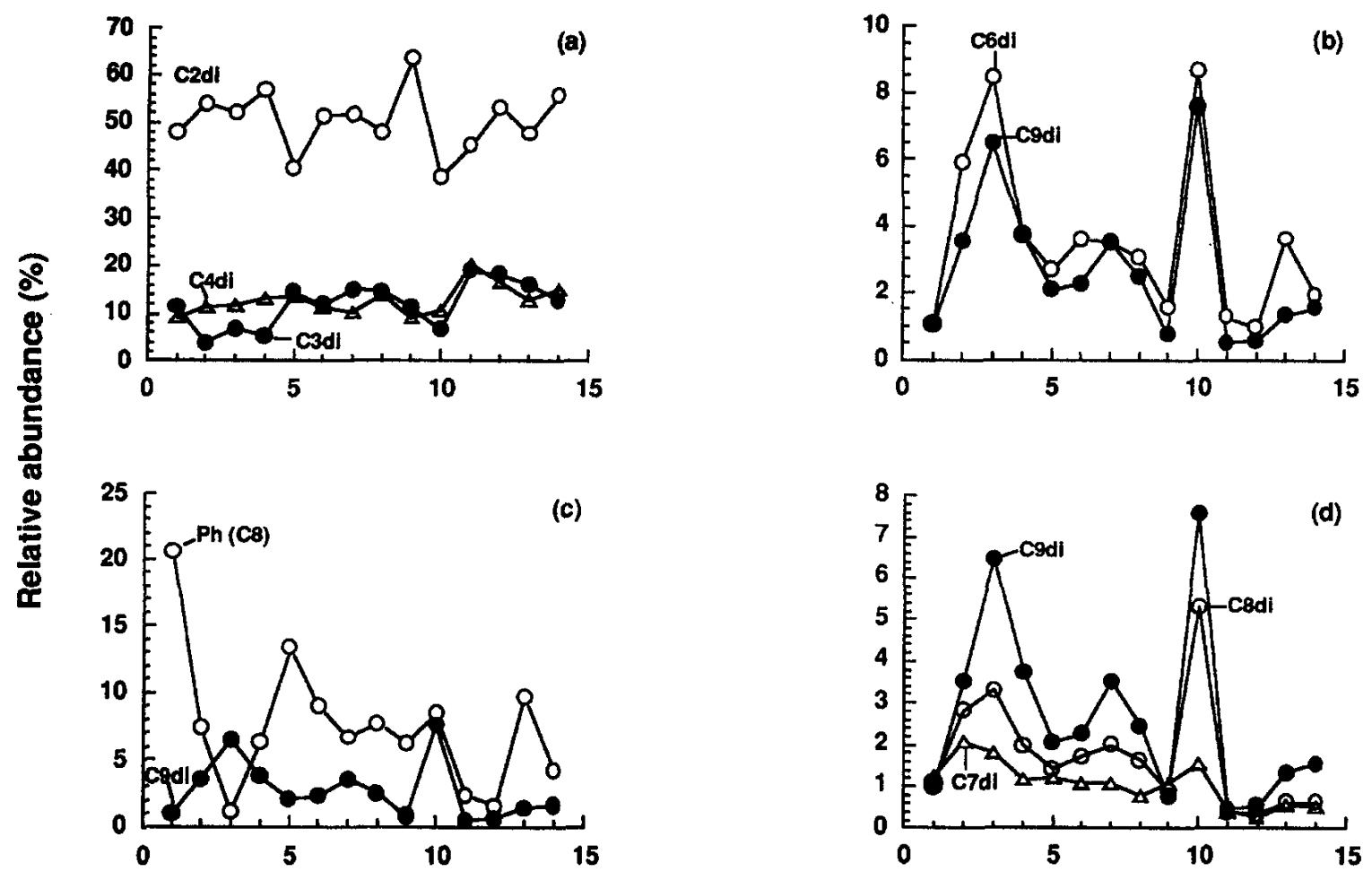

Sample No.

Fig. 4. Relative abundance of individual dicarboxylic acids in the western Pacific rainwater samples, September-October 1992: (a) oxalic acid $\left(C_{2}\right)$, malonic $\left(C_{3}\right)$ and succinic acids $\left(C_{4}\right) ;(b)$ adipic $\left(C_{6}\right)$ and azelaic acids $\left(C_{9}\right)$; (c) phthalic $\left(C_{8}\right)$ and azelaic acids; (d) pimelic acid $\left(C_{7}\right)$, suberic $\left(C_{8}\right)$ and azelaic acids.

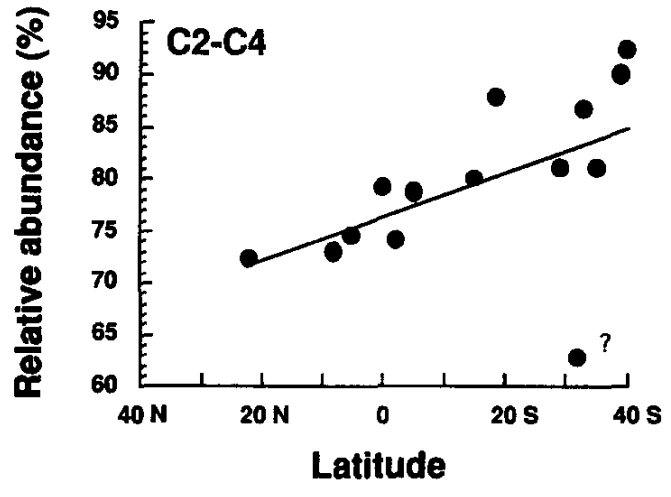

Fig. 5. Latitudinal changes in the relative abundance (\%) of cumulated $\mathrm{C}_{2}-\mathrm{C}_{4}$ dicarboxylic acids including oxalic, malonic, methylmalonic, oxomalonic, maleic and succinic acids in the total diacids $\left(\mathrm{C}_{2}-\mathrm{C}_{10}\right)$ in the western Pacific rainwater samples, September-October 1992.

$0.5-8 \%$ (av. 3\%) of the total diacid, respectively. Interestingly, phthalic acid was the second most abundant in the $\mathbf{R} 1$ sample ( $21 \%$ ) whereas it represents less than $10 \%$ in the other marine rains (Table 3; Fig. 4c). Ester forms of this compound are used as plasticisers. Phthalic acid has been reported in high concentrations in Los Angeles (Kawamura et al., 1985; Simoneit and Mazurek, 1989) and Tokyo aerosol samples (Kawamura and Ikushima, 1993; Sempéré and Kawamura, 1994) as well as in Tokyo precipitation samples (Sempéré and Kawamura, 1994). This aromatic acid is potentially derived by the atmospheric oxidation of polynuclear aromatic hydrocarbons such as naphthalene (Kawamura and Ikushima, 1993). Our results suggest that an anthropogenic source is more significant in western North Pacific (R1) well known to receive dust particles from China and other Asian countries (Duce et al., 1990). However, marine sources producing phthalic acid cannot be precluded because phthalic acid was abundantly detected in the remote marine rainwaters.

The $\mathrm{C}_{9}$ diacid has been considered as a unique photochemical oxidation product of biogenic unsaturated fatty acids which contain a double bond predominantly at $\mathbf{C}_{9}$. position (Kawamura and Kaplan, 1983; Yokouchi and Ambe, 1986; Kawamura and Gagosian, 1987). Relative abundance of azelaic acid in the total diacids ranged from c. $0.5 \%$ (R11) to c. $8 \%(\mathrm{R} 10)$. Interestingly, relative abundance of $\mathrm{C}_{9}$ diacid showed a negative correlation with that of phthalic acid in the samples (R1-R7) collected in the Northern Hemisphere and equatorial Pacific (Fig. 4c). On the other hand, glutaric $\left(C_{5}\right)$ and adipic $\left(C_{6}\right)$ acids have been reported as ozone oxidation products of cyclohexene (Grosjean et al., 1978; Hatakeyama et al., 

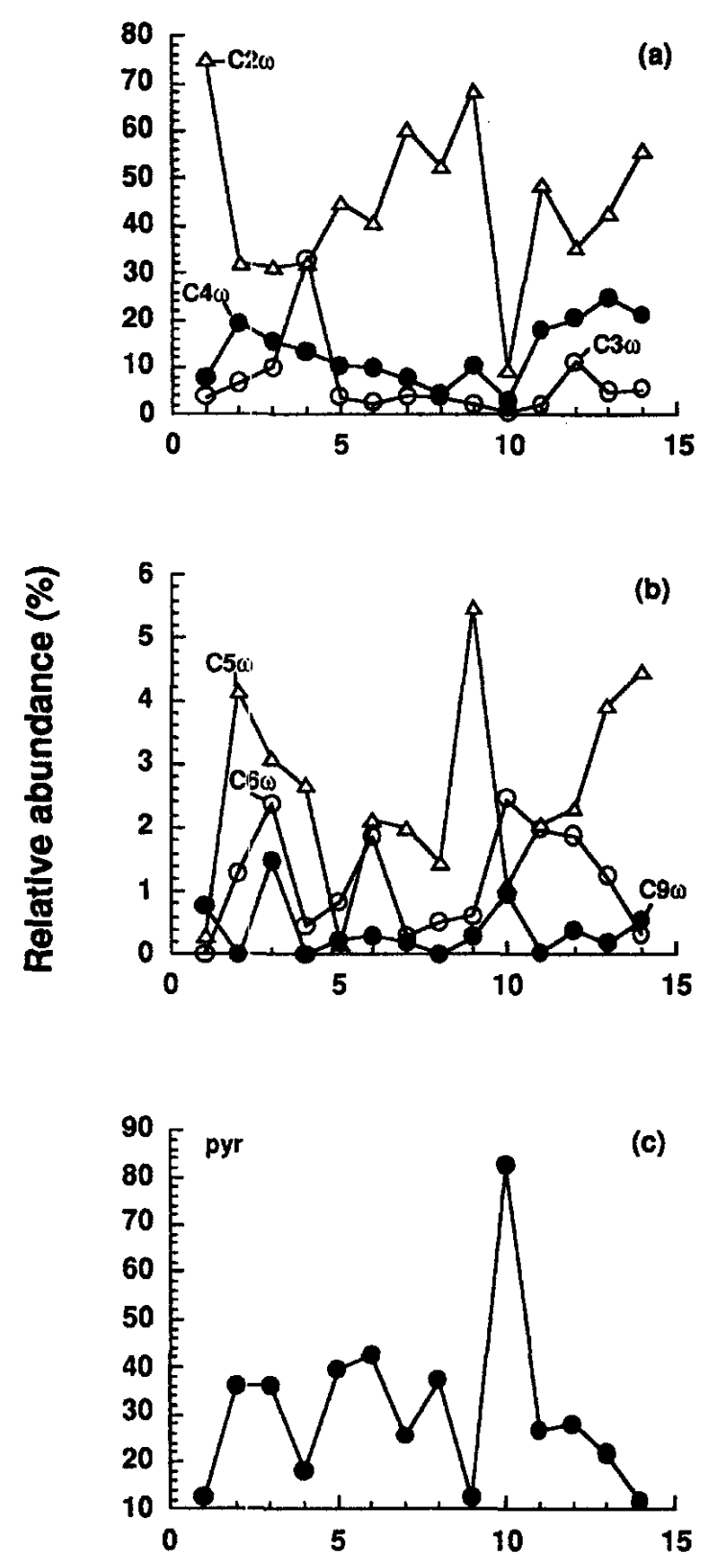

Sample No.

Fig. 6. Relative abundance of individual $\omega$-oxoacids and pyruvic acid in the western Pacific rainwater samples, September-October 199:2: (a) glyoxylic $\left(\mathrm{C}_{2}\right)$, 3-oxopropanoic, and 4-oxobutanoic acids; (b) 5-oxopentanoic, 6-oxohexanoic and 9-oxononanoic acids; (c) pyruvic acid $\left(\mathrm{C}_{8}\right)$.

1985) and considered as a potential tracer of continental aerosol (Kawamura and Usukura, 1993). However, the $\mathrm{C}_{6}$ diacid comprised only $1 \%$ of the total diacid in the $\mathbf{R} 1$ sample, which was collected in the mid-latitude of western North Facific (Fig. 1). The relative abundance of $\mathrm{C}_{6}$ diacid rather showed a parallel distribution with that of $\mathrm{C}_{9}$ diacid (Fig. $4 \mathrm{~b}$ ), suggesting that adipic acid may be of natural origin in the remote rainwater. It is likely that the former considerations based on laboratory simulation (Hatakeyama et al., 1985) and urban aerosol studies (Kawamura and Ikushima,
1993) are not valid for wet precipitation in the remote marine atmosphere.

Pyruvic or glyoxylic acid was the dominant ketoacid, the longer chain $\omega$-oxoacids being less abundant (Fig. 6). However, the chain length distributions of $\omega$-oxoacids seems to be consistent with those of $\alpha, \omega$-dicarboxylic acid. The parallel distributions suggest that these LMW $\omega$-oxoacids are one of the precursors of LMW $\alpha, \omega$-dicarboxylic acids. It is of interest to note that pyruvic acid $\left(C_{3}\right)$ is either the second or first dominant ketoacid species, being in good agreement with previous urban studies (Kawamura and Ikushima, 1993; Sempéré and Kawamura, 1994) suggesting a different source for pyruvic and $\omega$-oxoacids. Moreover, the lifetime of pyruvic acid is rather short (few hours) suggesting that the occurrence in rain samples of this species is mainly due to an in situ production rather than long-range transport. Interestingly, glyoxylic and pyruvic acids have been detected in eastern Pacific seawaters (Steinberg and Bada, 1984). The authors found pyruvic and glyoxylic acid concentrations at $75 \mathrm{~m}$ depth (no samples in the surface waters) to be 20 and $5 \mu \mathrm{g} \ell^{-1}$, respectively. These values are also in the same order of magnitude as those reported for marine rainwater samples (Table 2). These ketoacids are probably more abundant in the surface waters due to stronger biological activities (Bada et al., 1982) and may in part contribute to the ketoacids in the marine atmosphere.

$\omega$-Oxononanoic acid $\left(\mathrm{C}_{9}\right)$, a unique photooxidation product of biogenic unsaturated fatty acids whose double bond exists predominantly at the $\mathrm{C}_{9}$ position (Kawamura and Gagosian, 1987) was also detected in some rain samples as only minor species. A similar trend was also observed in the relative abundance of $\mathrm{C}_{9}$ diacid (Fig. 4b). Interestingly, this compound was found to be more abundant in the remote aerosol samples collected over the ocean in the same area (Sempéré and Kawamura, in press). The difference in the molecular distribution of $\mathrm{C}_{9} \omega$-oxoacid between aerosol and rain may suggest that the $\omega$-oxoacid is further oxidised to corresponding diacid and related compounds in the upper levels of the troposphere and/or in the rain droplets.

Cis/trans configuration of unsaturated dicarboxylic acids in urban atmosphere

Two aliphatic unsaturated diacids were detected in the marine rain samples: maleic (cis configuration) and fumaric acid (trans configuration). Interestingly, the cis/trans ratio showed a diversity ranging from 0.5 to 3.8 (av. 1.3). The $\mathrm{M} / \mathrm{F}$ ratio is probably controlled by the production of maleic acid from the photochemical oxidation of benzene (Bandow et al., 1985) and the subsequent isomerisation to fumaric acid (Kawamura and Ikushima, 1993). Alternatively, maleic acid may be produced from marine derived aromatics including phenolic materials, which have been reported to originate from macro algae and 
enrich in the microlayers of seawater (Carlson, 1982). It is of interest to note that $\mathrm{M} / \mathrm{F}$ ratios are lower than those (av. 5.8) from Tokyo rain samples (Sempéré and Kawamura, 1994). It is likely that the maleic acid production is enhanced in the urban atmosphere, whereas in remote areas the cis-trans isomerisation may prevail in the control of maleic acid concentration.

\section{CONCLUSIONS AND SUMMARY}

Remote marine rainwater samples collected over the western North Pacific showed the presence of homologous series of dicarboxylic acids $\left(\mathrm{C}_{2}-\mathrm{C}_{10}\right)$ as well as ketoacids $\left(\mathrm{C}_{2}-\mathrm{C}_{9}\right)$ and dicarbonyls $\left(\mathrm{C}_{2}-\mathrm{C}_{3}\right)$. In all the rain samples, oxalic $\left(\mathrm{C}_{2}\right)$ acid was found as the most abundant diacid species followed by malonic $\left(\mathrm{C}_{3}\right)$ or succinic $\left(\mathrm{C}_{4}\right)$ acid. Longer chain diacids are generally less abundant.

The concentrations of total diacids were found as high as $959 \mu \mathrm{g} \ell^{-1}$. The concentration level (av. $237 \mu \mathrm{g} \ell^{-1}$ ) was unexpectedly high compared to continental rainwater (e.g. $12-540 \mu \mathrm{g} \ell^{-1}$ for Tokyo rains). High concentrations were interpreted by (1) long-range atmospheric transport of continental air mass containing diacids and related polar compounds, and (2) production of diacids in the marine atmosphere by photo-induced oxidation of $>\mathrm{C}_{3}$ organic precursors of both continental and marine origin. Ketoacids such as glyoxylic $\left(\mathrm{C}_{2}\right)$ and pyruvic $\left(\mathrm{C}_{3}\right)$ acids are likely intermediates to result in oxalic acid. Photochemical production and subsequent accumulation were supported by the higher relative abundance of oxalic acid (av. 50\%) in the remote marine rainwater than that of continental rain/snow $(28-33 \%)$ and Greenland snow/ice $(28 \%)$ samples.

The dicarboxylic acids were found as the important chemical species of rainwater DOC (av. $1.6 \mathrm{mgC} \ell^{-1}$ ), accounting for up to $5 \%$ (av. 3\%) of DOC. These values are $c .3$ times higher than that of continental rainwaters. This study suggested that, in the remote marine atmosphere, organic compounds originated from either long-range transport of continental sources or sea-to-air emission of marine organic matter are subjected to photochemical oxidations to produce oxalic acid and other polar compounds.

Acknowledgements-The authors are very grateful to $\mathrm{K}$. Tanaka for the help of sample collection. We wish to acknowledge the Japan Society for the Promotion of Science (JSPS) for the post-doctoral fellowship to R. S as well as useful comments of referees. The authors appreciated the help of Dr France Van Wambeke for drawing Fig. 1. This study was in part supported by the Ministry of Education, Science and Culture through Grant-in-Aid No 06453009.

\section{REFERENCES}

Atlas E. and Giam C. S. (1981) Global transport of organic pollutants: Ambient concentrations in the remote marine atmosphere. Nature 211, 163-165.
Bada J. L., Hoopes E. and Ho M. S. (1982) Combined amino acids in Pacific Ocean waters. Earth Planet. Sci. Lett. 58, 276-284.

Bandow H., Washida N. and Akimoto H. (1985) Ring-cleavage reactions of aromatic hydrocarbons studied by FT-IR spectroscopy. I. Photooxidation of toluene and benzene in the $\mathrm{NO}_{x}$-air system. Bull. Chem. Soc. Japan. 58, 2531-2540.

Barger W. R. and Garret W. D. (1970) Surface active organic material in the marine atmosphere, J. geophys. Res. 75, 4561-4566.

Carlson D. J. (1982) Surface microlayer phenolic enrichments indicate sea surface slicks. Nature 296, 426-429.

Cronn D. R., Charlson R. J., Knight R. L., Crittenden R. L. and Appel B. R. (1977) A survey of the molecular nature of primary and secondary components of particles in urban air by high-resolution mass spectroscopy. Atmospheric Environment 11, 929-937.

Duce R. A. and Duursma E. G. (1977) Inputs of organic matter to the ocean. Mar. Chem. 5, 319-339.

Duce et al. (1990) The atmospheric input of trace species to the world ocean. Global Biogeochem. Cycles 5, 193-259.

Gagosian R. B., Peltzer E. T. and Zafiriou O. C. (1981) Atmospheric transport of continentally derived lipids to the tropical North Pacific. Nature 291, 8312-8314.

Gagosian R. B., Peltzer E. T. and Merril J. T. (1987) Longrange transport of terrestrially derived lipids in aerosols from the South Pacific. Nature 325, 800-803.

Grosjean D. and Friedlander S. K. (1980) Formation of organic aerosols from cyclic olefins and diolefins. Adv. Envir. Sci. Technol. 9, 435-473.

Grosjean D., Van Cauwenberghe K., Schmid J. P., Kelley P. E. and Pitts J. N. Jr. (1978) Identification of $C_{3}-C_{10}$ aliphatic dicarboxylic acids in airborne particulate matter. Envir. Sci. Technol. 12, 313-317.

Hatakeyama S., Tanonaka T., Weng J., Bandow H., Tagaki H. and Akimoto H. (1985) Ozone-cyclohexene reaction in air: quantitative analysis of particulate products and the reaction mechanisms. Envir. Sci. Technol. 19, 935-942.

Hoigné J., Zuo Y. and Nowell L. (1994) Photochemical reactions in atmospheric waters: role of dissolved iron species. In Aquatic and Surface Photochemistry (edited by G. R. Helz et al.), pp. 75-84. CRC Press, Boca Raton, Florida.

Kawamura K. (1993) Identification of $\mathrm{C}_{2}-\mathrm{C}_{10}$ w-oxocarboxylic acids, pyruvic acid, and $\mathrm{C}_{2}-\mathrm{C}_{3} \alpha$-dicarbonyls in wet precipitation and aerosol samples by capillary GC and GC/MS. Anal. Chem. 65, 3505-3511.

Kawamura K. and Gagosian R. B. (1987) Implications of $\omega$-oxocarboxylic acids in the remote marine atmosphere for photo-oxidation of unsaturated fatty acids. Nature 325, 330-332.

Kawamura K. and Gagosian R. B. (1988) Identifications of aliphatic keto carboxylic acids in marine aerosols using capillary gas chromatography-mass spectrometry. $J$. Chromat. 438, 299-307.

Kawamura K. and Gagosian R. B. (1990) Atmospheric transport of soil-derived dicarboxylic acids over the North Pacific Ocean. Naturwissenschaften 77, 25-27.

Kawamura K. and Ikushima K. (1993) Seasonal changes in the distribution of dicarboxylic acids in the urban atmosphere. Envir. Sci. Technol. 27, 2227-2235.

Kawamura K. and Kaplan I. R. (1983) Organic compounds in the rainwater of Los Angeles. Envir. Sci. Technol. 17, 497-501.

Kawamura K. and Kaplan I. R. (1987) Motor exhaust emissions as a primary source for dicarboxylic acids in Los Angeles ambient air. Envir. Sci. Technol. 21, 105-110.

Kawamura K. and Kaplan I. R. (1991) Organic compounds in rainwater. In Organic Chemistry of the Atmosphere (edited by Hansen L. D. and Eatough D. J.), pp. 233-284, CRC Press, Boca Raton, Florida. 
Kawamura K. and Usukura K. (1993) Distributions of low molecular weight dicarboxylic acids in the North Pacific aerosol samples. J. Oceanogr. 49, 271-283.

Kawamura K. and Yasui O. (1991) Organic acids and aldehydes in the ice samples from Site-J, Greenland. Bull. Glacier. Res. 9, 59-63.

Kawamura K., Steinberg S. and Kaplan I. R. (1985) Capillary GC determination of short-chain dicarboxylic acids in rain, fog, and mist. Int. J. Envir. Anal. Chem. 19, 175-188.

Kawamura K., Sempéré R., Kasukabe K., Hayashi M. and Fujii Y. (1992) Dicarboxylic acids in the Antarctic aerosols. Proc. 3rd IGAC Symp in Japan, 10-11 December 1992. Nagoya University.

Kawamura K., Kasukabe H., Yasui O. and Barrie L. A Production of dicarboxylic acids in the arctic atmosphere at polar sunrise. Geophys. Res. Lett. (in press).

Khwaja H. A. (1995) Atmospheric concentrations of carboxylic acids and related compounds at a semiurban site. Atmospheric Environment 29, 127-139.

Li S. M. and Winchester J. W. (1993) Water soluble organic constituents in artic aerosols and snow pack. Geophys. Res. Lett. 20, 45-48.

Likens G. E., Edgerton E. S. and Galloway J. N. (1983) The composition and deposition of organic carbon in precipitation. Tellus 35B, 16-24.

Liljestrand H. M. and Morgan J. J. (1980) Spatial variations of acid precipitations in Southern California. Envir. Sci. Technol. 15, 333-339.

Liss P. S. (1973) Processes of gas exchange across an airwater interface. Deep Sea Res. 20, 221-238.

Lunde F., Gether J., Gjos N. and Lande M. S. (1977) Organic micropollutants in precipitation in Norway. Atmospheric Environment 11, 1007-1014.

Marty J. C., Saliot A., Buat-Menard P., Chesselet R. and Hunter K. A. (1979) Relationship between the lipid compositions of marine aerosols, the sea surface microlayer and subsurface water. J. geophys. Res. 84, 5705-5716.

Norton R. B., Roberts .J. M. and Huebert B. J. (1983) Tropospheric oxalate. Geophys. Res. Lett. 10, 517-520.

Ratte M., Plass-Dulmer C., Koppmann R., Rudolph J. and Denga J. (1993) Production mechanisms of $\mathrm{C}_{2}-\mathrm{C}_{4}$ hydrocarbons in seawater: field measurements and experiments. Global Biogeochem. Cycles 7, 369-378.
Schuetzle D., Cronn D. and Crittenden A. L. (1975) Molecular composition of secondary aerosols and its possible origin. Envir. Sci. Technol. 9, 838-845.

Sempéré R. and Kawamura K. (1994) Comparative distributions of dicarboxylic acids and related polar compounds in snow, rain and aerosols from urban atmosphere. Atmospheric Environment 28, 449-459.

Sempéré R. and Kawamura K. Molecular distribution changes of diacids and related polar compounds in aerosols during long range transport (in press).

Simoneit B. R. T. (1977) Organic matter in eolian dusts over the Atlantic Ocean. Mar. Chem. 5, 443-464.

Simoneit B. R. T. and Mazurek M. A. (1989) Organic tracers in ambient aerosols and rains. Aerosol Sci. Technol. 10, 267-291.

Smith K. L. Jr. (1987) Food energy supply and demand: a discrepancy between particulate organic carbon flux and sediment community oxygen consumption in the deep ocean. Limnol. Oceanogr. 32, 201-220.

Steinberg S. M. and Bada J. L. (1984) Oxalic acid, glyoxalic and pyruvic acids in eastern Pacific Ocean waters. J. Mar. Res. 42, 697-708.

Stephanou E. G. (1992) $\alpha, \omega$-Dicarboxylic acid salts and $\alpha, \omega$-dicarboxylic acids. Naturwissenshaften 79, 128-131.

Stephanou E. G. and Stratigakis N. (1993) Oxocarboxylic and dicarboxylic acids: Photooxidation products of biogenic unsaturated fatty acids present in urban aerosols. Envir. Sci. Technol. 27, 1403-1407.

Woodcock A. H. (1953) Salt nuclei in marine air as a function of altitude and wind force. J. Meteorol. 10, 362-371.

Yokouchi Y. and Ambe Y. (1986) Characterization of polar organics in airborne particulate matter. Atmospheric Environment 20, 1727-1734.

Zafiriou O. C., Gagosian R. B., Pelzer E. T., Alford J. B. and Loder T. (1985) Air-to sea fluxes of lipids at Enewetak Atoll. J. geophys. Res. 90, 2409-2423.

Zuo Y. and Hoigné J. (1992) Formation of hydrogen peroxide and depletion of oxalic acid in atmospheric water by photolysis of iron (III)-oxalato complexes. Envir. Sci. Technol. 26, 1014-1022.

Zuo Y. and Hoigné J. (1994) Photochemical decomposition of oxalic and pyruvic acids catalysed by iron in atmospheric waters. Atmospheric Environment 28, 1231-1239. 